\title{
Effective Parameter of Nano-CuO Coating on CO Gas-Sensing Performance and Heat Transfer Efficiency
}

\author{
M. H. Mahmood ${ }^{1}$ D $\cdot$ M. A. Maleque ${ }^{1}$
}

Received: 9 May 2020 / Accepted: 9 December 2020 / Published online: 5 January 2021

(c) The Author(s) 2021

\begin{abstract}
The high gas-sensing performance of semiconductors is mainly due to the high surface-to-volume ratio because it permits a large exposed surface area for gas detection. This paper presents an evaluation study for the effects of nano-CuO coating parameters on the $\mathrm{CO}$ gas-sensing performance. The effects on gas-sensing performance and heat transfer efficiency of $\mathrm{CuO}$ coating were evaluated by investigating the effects of coating parameters (concentration, temperature, and solution speed) on thickness, grain size, and porosity. The $\mathrm{CuO}$ nanoparticle coatings were synthesized using the oxidation method at various operating conditions. Coating characteristics were investigated using X-ray diffraction, energy dispersive X-ray Spectroscopy, field emission scanning electron microscopy, and electrical resistivity meter. The average coating thickness, grain size, and porosity were around $13 \mu \mathrm{m}, 48 \mathrm{~nm}$, and $30 \%$, respectively. The thermal transfer and gas-sensing properties of $\mathrm{CuO}$ coating were evaluated according to the total surface area of the coating formed at various operating conditions. The gas-sensing and thermal transfer performance were obtained from the optimization of coating parameters based on the coating morphology to achieve the highest contact surface area. The coating's surface area was increased by 350 times, which improved the heat transfer efficiency of $96.5 \%$. The result shows that the coating thickness increased with the increase in solution concentration and decrease the temperature. The results also show that the sensitivity of the coating for $\mathrm{CO}$ gas was increased by $50 \%$ due to the reduction of coatings grain size.
\end{abstract}

Keywords Nano-CuO coating $\cdot$ Coating parameters $\cdot \mathrm{CO}$ gas sensitivity $\cdot$ Heat transfer

\section{Introduction}

Cupric oxide $(\mathrm{CuO})$ is a cheaper and nontoxic abundant material [1-4]. It also has fabulous properties, high stability [5], excellent catalytic activity [6], superconducting [4], good optical properties [2], and a fabulous antibacterial activity $[5,7]$. Therefore, this low-cost material is preferred to be used in gas-sensing applications when compared with other rare expensive materials [5]. It is classified as an easily obtainable $p$-type semiconductor with bulk band gap range between 1.21 and $2.1 \mathrm{eV}$ [3]. It has a complex crystallographic monoclinic structure. Recently, nanostructures $\mathrm{CuO}$ has been extensively used in manufacturing gas sensors because of its effective $p$-type properties [5, 8]. As

M. H. Mahmood

mahmoodfattah@yahoo.com

1 Department of Manufacturing and Material Engineering, International Islamic University Malaysia, PO Box 10, 50728 Kuala Lumpur, Malaysia a semiconductor, it has high electrical resistivity compared to the copper metal. Previous studies reported that the electrical resistivity of $\mathrm{CuO}$ is in the range of $10^{4}$ to $10^{6} \Omega \mathrm{cm}$, for coating prepared by electrodeposition oxidation, and $10^{2}$ to $10^{4} \Omega \mathrm{cm}$ for coating prepared by thermal oxidation [9]. Nanosized $\mathrm{CuO}$ has been employed in the manufacturing of various gas sensors to detect the reducing and oxidizing gases include $\mathrm{H}_{2}, \mathrm{H}_{2} \mathrm{~S}, \mathrm{CO}, \mathrm{CO}_{2}, \mathrm{NH}_{3}, \mathrm{CH}_{4}$, and $\mathrm{NO}$, as well as some volatile organic compounds like formaldehyde, ethylene, propene, propane, methanol, ethanol, acetone, and toluene [10-12].

The mechanism of $p$-type gas-sensing semiconductor can be explained by the changes in resistance caused by the adsorption reactions of gas molecules on the surface of the sensor. The sensing performance of gas sensors is related to the surface morphology that affects electrical resistance [13]. Generally, the reduction of gases such as $\mathrm{H}_{2} \mathrm{~S}, \mathrm{NH}_{3}$, $\mathrm{CO}, \mathrm{H}_{2}, \mathrm{SO}_{2}, \mathrm{CH}_{4}$, and $\mathrm{HCHO}$ by $p$-type semi-conductors leads to the decrease in resistance, while the reversed effect was observed for oxidizing gases such as $\mathrm{NO}, \mathrm{N}_{2} \mathrm{O}, \mathrm{NO}_{2}$, 
$\mathrm{CO}_{2}, \mathrm{O}_{3}$, and $\mathrm{Cl}_{2}[14,15]$. For example, when $\mathrm{CuO}$ gas sensor is exposed to air, the surface of the sample will absorb the oxygen molecules. The absorbed oxygen tends to trap the electrons from the $\mathrm{CuO}$ layer band to form $\mathrm{O}^{2-}$ leading to a decrease in electron density on the surface, causing a rapid decrease in the resistance.

The surface morphology of the gas sensor firmly depends on the coating techniques and its operating parameters. The surface gas-sensing performance and heat transfer efficiency of any sensors can be enhanced by controlling the coating parameters such as concentration, temperature, and solution speed. Therefore, this study presents the effective parameters of nano-CuO coating on $\mathrm{CO}$ gas-sensing performance and heat transfer efficiency.

\section{Materials and Methods}

To study the effects of coating process parameters on nano- $\mathrm{CuO}$ coating, an electrochemical oxidation method in oxalic acid solution at various operating conditions was established. The testing samples were prepared from pure copper foil of $99.5 \%$ purity, with the dimension of $1 \times 1 \mathrm{~cm}$ and thickness of $0.12 \mathrm{~mm}$. These samples were polished using emery papers and chemically cleaned according to the ASTM International standard of B 281-88 [16]. The sample was soaked in distilled water and acetone, respectively, and then dried in the air. All experiments were performed using a three-electrode electrochemical cell consists of copper as the working electrode, silver/silver chloride $(\mathrm{Ag} / \mathrm{AgCl})$ (SSE) as the reference electrode, and platinum sheet as the counter electrode. The experiments were performed using the linear sweep voltammetry (LSV) method at the scan rate of $0.02 \mathrm{v} / \mathrm{s}$, by means of Potentiostat/Galvanostat Auto-Lab, PGSTAT AUT86037, as reported in previous article [17]. The selected coating parameters include the temperature between 0 and $24{ }^{\circ} \mathrm{C}$ and oxalate concentration between 0.1 and $0.5 \mathrm{M}$. The effects of these parameters on the coating morphology were optimized to achieve the highest contact surface area to improve the gas-sensing and the thermal transfer performance. The speed of the coating solution was considered as a noise factor on the charge transfer and coating rate. Therefore, the effects of the solution speed on coating thickness and microstructure were investigated at the solution angular velocities of 0,100 , and 300 runs per min (RPM), which corresponding to the linear solution speed of $0.00,0.18$, and $0.55 \mathrm{~m} / \mathrm{s}$, respectively. The fully factorial parameters are shown in Table 1.

The coated thin films' electrical resistance was measured using Loresta resistivity meter, model MCP T400, from Mitsubishi. This device measures the thin film's sheet electrical resistance, and then, the thin film thickness can be calculated using these measurements. The device consists of four-point
Table 1 Presentation of fully factorial parameters

\begin{tabular}{lcll}
\hline \multicolumn{2}{l}{ Coating parameters } & Responses \\
\hline $\begin{array}{l}\text { Concen- } \\
\text { tration } \\
(\mathrm{M})\end{array}$ & $\begin{array}{l}\text { Tempera- } \\
\text { ture }\left({ }^{\circ} \mathrm{C}\right)\end{array}$ & Solution speed $(\mathrm{m} / \mathrm{s})$ & $\begin{array}{l}\text { Coating morphology } \\
0.1\end{array}$ \\
0.23 & 8 & $0-0.55$ & Grain size, thickness \\
0.36 & 16 & & \\
0.5 & 24 & & \\
\hline
\end{tabular}

tungsten probes. The electrical resistance was measured by contacting the four probes on the surface. High impedance current source was used to supply current through the two outer probes, while a voltmeter was used to measure the voltage across the inner two probes to determine the resistivity of the sample. When probes with uniform spacing $(S)$ is placed on a film thickness of (th) the resistivity $(r)$ can be expressed as follows:

$r=2 \pi s \frac{V}{I} \mu \Omega-\mathrm{cm}(\mathrm{th}>>s)$

The electrical resistivity of a bulk material was calculated using Eq. (1), while the thin films resistivity was calculated using Eq. (2).

$r=\left\{\frac{\pi t}{\ln 2}\right\} \frac{V}{I} \mu \Omega-\mathrm{cm} \quad(s>>$ th $)$

The sheet resistance of the coated samples was measured with the four-point probe by dividing the voltage drop $(V)$ between the two inner probes over the passing current $(I)$ between the two outer probes.

The results were multiplied by a geometric correction factor that depends on the probe geometry. The average coating resistance (Rsh) and resistivity $(r)$ were $270 \mathrm{M} \Omega / \mathrm{sq}$ and $341 \mathrm{k} \Omega$, respectively. Note that the obtained coating resistance value was from the average of five measurements for each sample according to Eq. (3).

$\mathrm{Rsh}=\left\{\frac{\pi}{\ln 2}\right\} \frac{V}{I}=4.53 \frac{V}{I}$

The sheet resistance is sorted as a function of the material specification, it is independent of the geometrical dimension of the coated samples. Therefore, the resistance for a rectangular sample was considered as follows:

$R=r \frac{L}{w \times \text { th }}$

For a square sample, $L=w$ hence, sheet resistance (Rsh) is considered as the ratio of the resistivity $(r)$ of the films to their thickness (th) [9]. 
$R=\frac{r}{\text { th }}=\mathrm{Rsh}$

Sheet resistance is treated as the resistance of a square sample, the units of sheet resistance (Rsh) are taken to be Ohms-per-square $(\Omega / s q)$. From this equation, the film thickness (th) was measured by dividing resistivity to sheet resistance as in Eq. (6) [18].

th $=\frac{r}{\mathrm{Rsh}}$

The gas-sensing response $(R)$ is defined as the ratio of the resistance values of the sensor; in the detected gas to the resistance in the air; $R=\mathrm{Rg} / \mathrm{Ra}$ [6]. The highest sensitivity of $\mathrm{CO}$ gas sensor $(S)$ was calculated by the following equation [6];

$S(\%)=\frac{(\mathrm{Rg}-\mathrm{Ra})}{\mathrm{Ra}} \times 100$

In case of gas detection by an interface between two phases, the total surface area comprises the external and internal surface area, which is available to the detected gas. The total surface area (SA) can be defined as the result of the mass-specific surface area (SSA) multiplied by the mass of the accessible surface area.

$\mathrm{SA}=\mathrm{SSA} \times M$

where SA total surface area, SSA mass-specific surface area, and $M=$ mass of the accessible surface area.

The mass of the accessible surface area $M$ can be calculated by the following equation:

$M=$ th $\times \rho \times \mathrm{SA}$

where th average thickness, $\rho=$ average density of the surface, SA total surface area.

\section{Characterization of Nano coated Material}

Characterization of the coated samples phases was carried out using Bruker X-ray diffraction (XRD) testing machine with $\mathrm{Cu}-\mathrm{K} \alpha$ radiation, $\lambda=1.54 \AA$ at scanning rate of $0.02 \% \mathrm{~s}$ within the range of $20^{\circ}-80^{\circ}$. The XRD pattern of the coated sample is shown in Fig. 1. The XRD pattern shows prominent diffraction peaks at $35.5^{\circ}$ and $38.7^{\circ}$ which refer to the predominance of the monoclinic $\mathrm{CuO}$ nanostructure in the coating $[19,20]$. The coating grains were crystallites arranged in a specific orientation plane. The coating's Crystallite size was calculated from the corresponding X-ray spectral peak by employing Debye-Scherrer's formula. The calculation was based on the full-width half-maximum FWHM method. The Crystallite size of coating using the highest diffraction peak was $42 \mathrm{~nm}$.



Fig. 1 XRD pattern of $\mathrm{CuO}$ coated sample at $24{ }^{\circ} \mathrm{C}$ and $0.5 \mathrm{M}$ oxalate concentration

Chemical composition of anodized coating was characterized using energy-dispersive X-ray spectroscopy EDX revealed that the oxygen content in the coated samples reached $70 \mathrm{wt} \%$, which indicate the formation of copper oxide phase. From the XRD diffraction pattern and the EDX spectrum results, it was concluded that an anodized coating of copper oxide was successfully formed on copper using anodization electrochemical technique in oxalate solution.

The microstructure analysis for the coated samples was investigated using high-resolution field emission scanning electron microscopy (FESEM). This device is supported with a high energetic electrons beam generates by emitting from a heated tungsten source. The electron source joined with a scanning electron microscope (SEM) that supported a secondary electron detector. This microscope produces high-resolution surface imaging, which is due to its tiny electron beam size. It is about 1000 times smaller than that of the standard thermal electron gun microscope. The grain size was measured by the linear intercept analyzing method according to the ASTM E112-10 standard [21]. FESEM micrographic results were analyzed using image analyzing software. The images were analyzed using colored or B\&W background with applying the suitable gray threshold to create the best binary views for the grain size and distributions. The average grain size was measured in four directions $\left(0^{\circ}, 45^{\circ}, 90^{\circ}, 135^{\circ}\right)$ using the linear intercept method, according to ASTM standard test methods for determining average grain size. This method's first step is to set the line spacing in three directions horizontal, vertical, and 45 degrees. The 45 -degree line spacing was measured as (vertical/0.7) to plot lines of equal length in all directions, where the perpendicular distance between lines defined as $\left(\sin 45^{\circ}=0.707\right)$. The measured grain size smaller than three pixels was excluded from the calculations and considered noise. The grain size, $d$, was determined according to the following equation: 
$d=\frac{l}{n}$

where $l$ real lengths of the selected lines, $n$ number of grains that its boundary intercepted with that lines.

The pores percentage area of the samples was measured according to the ASTM standard test methods of E2109-1 [22]. Pores percentage area was measured in a selected region on images of the same magnification. The pores of small sizes, less than one pixel, were excluded from the calculations and considered noise. The pores percentage area was calculated from the percentage ratio of the area of the pores divided by the total cross-section area [22]. FESEM micrograph images were threshold with an appropriate range of gray values to create the best binary and three-dimensional view of pores distribution on the surface. Figure 2 shows well-distributed $\mathrm{CuO}$ nanoparticles prepared in oxalate solution. The coatings' average grain size and porosity were $\sim 44 \mathrm{~nm}$ and $\sim 8.5 \%$, respectively. The measurement methods for the investigation of coating morphological characteristics of grain size and porosity are also reported in another study [23].

\subsection{Thickness of Nanocoating}

The thickness of the coating prepared in various oxalate concentrations, temperatures, and voltage was measured using FESEM and checked by electrical resistivity (ER) methods. The average thickness for each coated sample was measured from five FESEM results according to the ASTM Standard B487-85 [24] using the distance measuring tools of the image analyzing software.

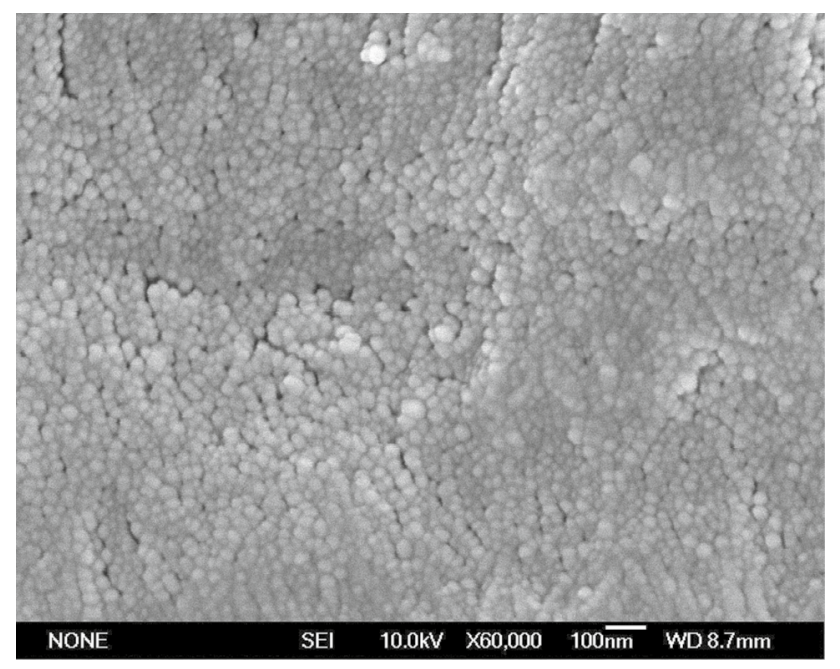

Fig. 2 Microstructure of nano-CuO coating prepared in oxalate solution
The coating thickness was also measured by the electrical resistance of the surface. The average measurements of three different points for each sample were taken. The results of the measured coating thickness by this method were compatible with the values measured from FESEM.

The effects of coating parameters such as temperature, oxalate concentrations, and voltage on the coating thickness were assessed using the Taguchi method. The coating was prepared at the oxalate concentration of $0.1,0.23,0.36$, and $0.5 \mathrm{M}$, temperatures of $0,8,16,24^{\circ} \mathrm{C}$, and voltage of $7.5,8$, 8.5 , and $9 \mathrm{~V}$. These experiments were used to evaluate the effects of various coating parameters on the coating thickness. The evaluation was based on the signal-to-noise $(\mathrm{S} / \mathrm{N})$ ratio as shown in the following equation:

$S / N=-10 * \log _{10}\left[\frac{1}{n} \sum \frac{1}{y i^{2}}\right]^{1}$

where $n$ number of observations, $y i$ average value of the coating thickness.

The results show that the average coating thickness was $13 \mu \mathrm{m}$. The results of coating thickness and the corresponding $S / N$ ratios are listed in Table 2.

The calculated values of $S / N$ ratios for varied coating thickness by factor levels are listed in Table 3 .

Figure 3 demonstrates the effects of coating parameters on the mean $S / N$ ratios considering the coating thickness. The result shows that the oxalate concentration in the coating solution was the most affecting parameter on the coating thickness, followed by the coating temperature.

Table 2 Average thickness of coating with their corresponding $S / N$ ratio

\begin{tabular}{llllll}
\hline Exp no. & $\begin{array}{l}\text { Temp } \\
\left({ }^{\circ} \mathrm{C}\right)\end{array}$ & $\begin{array}{l}\text { Oxalate } \\
\text { conc }(\mathrm{M})\end{array}$ & $\begin{array}{l}\text { Voltage } \\
(\mathrm{V})\end{array}$ & $\begin{array}{l}\text { Thickness } \\
(\mu \mathrm{m})\end{array}$ & $\begin{array}{l}S / N \\
\text { ratio }\end{array}$ \\
\hline 1 & 0 & 0.10 & 7.50 & 13.00 & 22.28 \\
2 & 0 & 0.23 & 8.00 & 14.20 & 23.05 \\
3 & 0 & 0.36 & 8.50 & 14.80 & 23.41 \\
4 & 0 & 0.50 & 9.00 & 17.00 & 24.61 \\
5 & 8 & 0.10 & 8.00 & 11.20 & 20.98 \\
6 & 8 & 0.23 & 7.50 & 12.50 & 21.94 \\
7 & 8 & 0.36 & 9.00 & 13.20 & 22.41 \\
8 & 8 & 0.50 & 8.50 & 15.60 & 23.86 \\
9 & 16 & 0.10 & 8.50 & 11.10 & 20.91 \\
10 & 16 & 0.23 & 9.00 & 11.50 & 21.21 \\
11 & 16 & 0.36 & 7.50 & 12.80 & 22.14 \\
12 & 16 & 0.50 & 8.00 & 13.80 & 22.80 \\
13 & 24 & 0.10 & 9.00 & 10.00 & 20.00 \\
14 & 24 & 0.23 & 8.50 & 10.50 & 20.42 \\
15 & 24 & 0.36 & 8.00 & 11.70 & 21.36 \\
16 & 24 & 0.50 & 7.50 & 14.80 & 23.41 \\
\hline
\end{tabular}


Table 3 Values of $S / N$ ratio of varied coating thickness

\begin{tabular}{llll}
\hline Level & Temperature $\left({ }^{\circ} \mathrm{C}\right)$ & $\begin{array}{l}\text { Concentration } \\
(\mathrm{M})\end{array}$ & Voltage $(\mathrm{V})$ \\
\hline 1 & 23.33 & 21.04 & 22.44 \\
2 & 22.30 & 21.66 & 22.05 \\
3 & 21.77 & 22.33 & 22.15 \\
4 & 21.30 & 23.67 & 22.06 \\
Delta & 2.04 & 2.63 & 0.39 \\
Rank & 2 & 1 & 3 \\
\hline
\end{tabular}



Fig. 3 Mean signal-to-noise ratio with respect to the average coating thickness as a function of the coating parameters

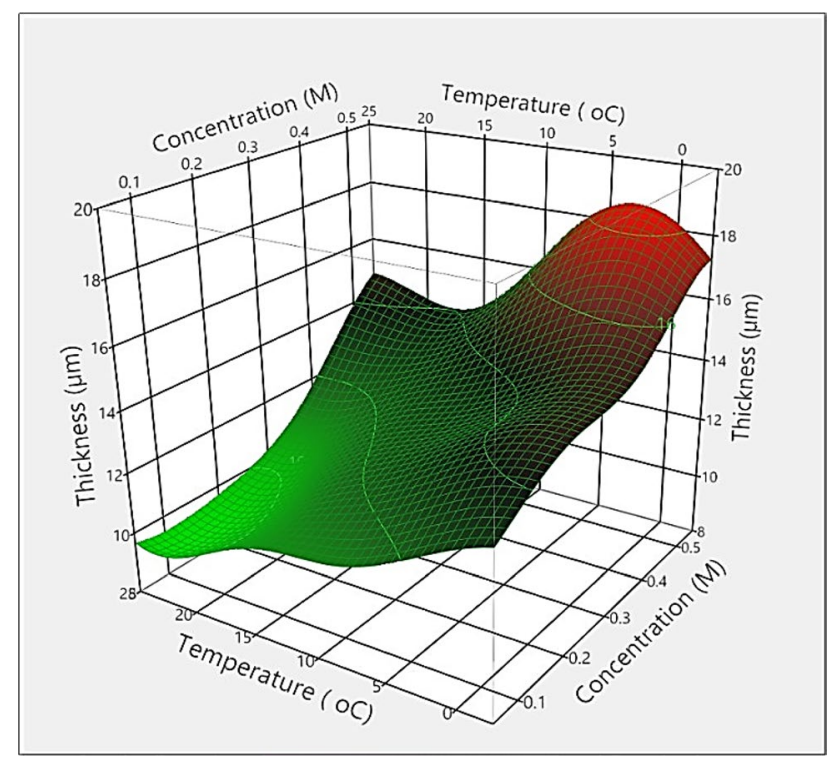

Fig. 4 The average thickness of the coating as a function of oxalate concentration and temperature

The results were further analyzed to evaluate the effect of temperature and oxalate concentration on the coating thickness. Figure 4 shows that the coating thickness decreased with the increase in coating temperature at the same

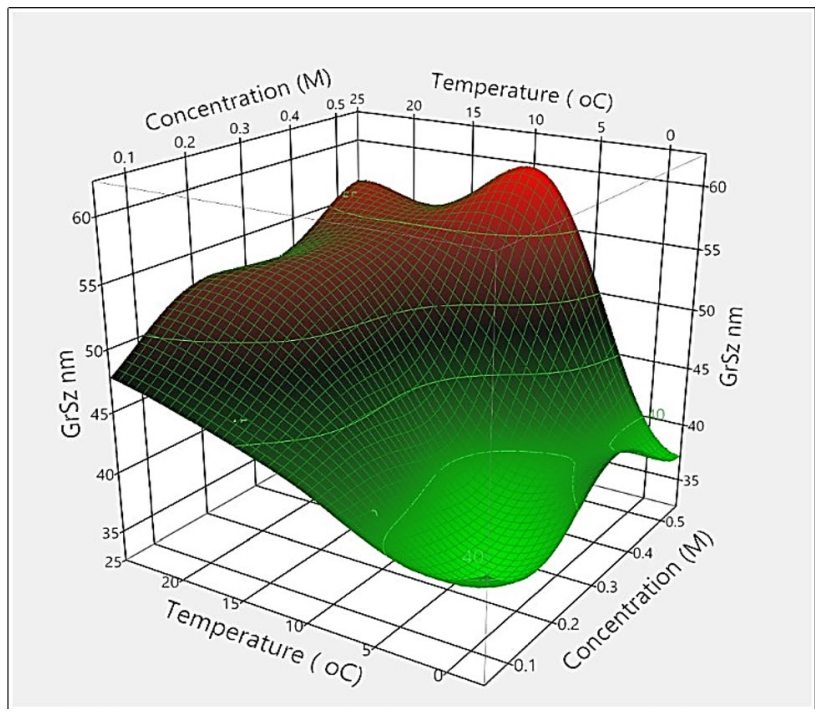

Fig. 5 Average grain size of the coating as a function of oxalate concentration and temperature

oxalate concentration. Meanwhile, the coating thickness was increased with the increase in the oxalate concentration at the same temperature. The increase in oxalate concentration at the same temperature increases the electrical conductivity of the coating solution. This is because the increased conductive ions in the solution led to an increase in the coating rate. Since the time of coating was the same for all experiments, the coating thickness increased with increasing oxalate concentration.

The results also show that the coating thickness decreased with the increase in coating temperature at the same oxalate concentration. This is due to the increase in the dissolution of cuprous oxide $\left(\mathrm{Cu}_{2} \mathrm{O}\right)$ as the temperature increased. In other words, the increase in temperature leads to a decrease in the coating thickness as a result of the rise in oxides dissolving rate.

\subsection{Grain Size and Porosity of Nanocoating}

The results also reveal that the decrease in temperature produced thicker coating with smaller grain size and less porosity, as shown in Figs. 5 and 6. This result is in line with the previous results [25]. The increased temperature increases the coating rate and the dissolution of the $\mathrm{Cu}_{2} \mathrm{O}$ in the solution. The results show that the temperature effect on coating dissolution was more than its effect on the coating rate. Therefore, the increase in coating temperature decreases the coating thickness. Similarly, the coating porosity increased with temperature as a result to the increase in $\mathrm{Cu}_{2} \mathrm{O}$ dissolution toward the solution [23], as shown in Fig. 6.

Recently, nanotechnology has been utilized in developing and enhancing material's optical, thermal, physical, and 


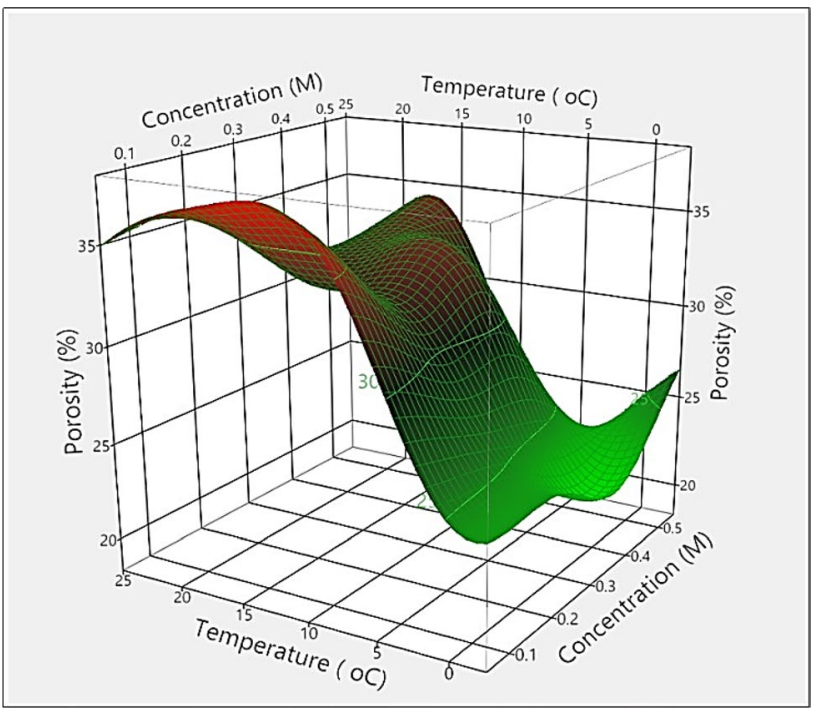

Fig. 6 Average porosity of coating as a function of oxalate concentration and temperature

mechanical properties [26]. The increase in surface area results in the increase in quantum effect, which enhances the material properties by increasing the surface-to-volume ratio. The microstructural surface characteristics are important due to their effects on the surface area, where reducing grain size leads to increased surface area according to the partition of surface particles into tiny parts. The calculations of total surface area for the coated samples show that the highest surface area was recorded at the highest oxalate concentration and lowest temperature as shown in Fig. 7.

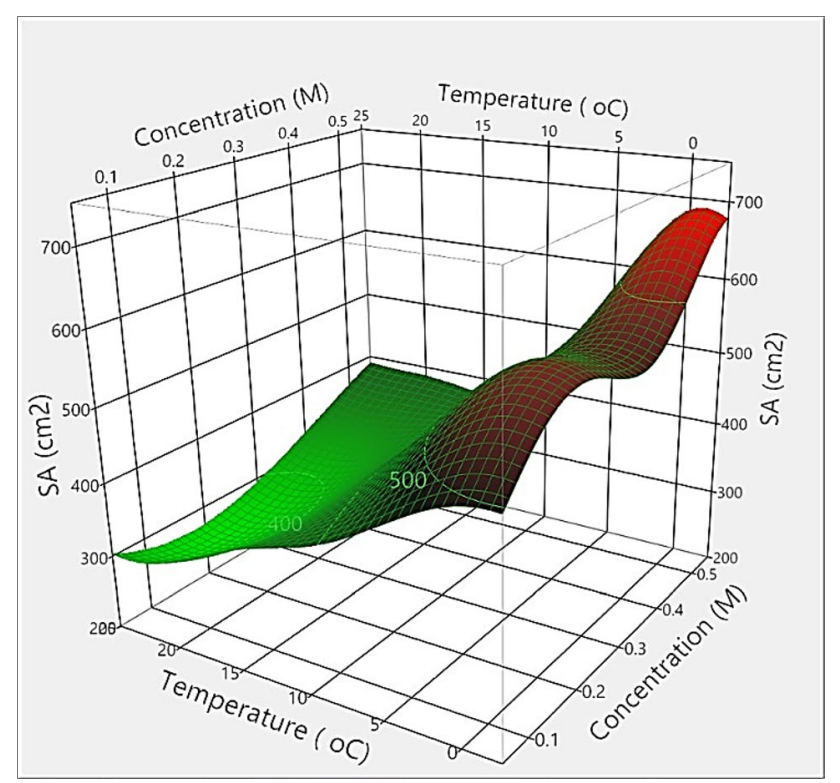

Fig. 7 The total surface area of coating as a function of coatings oxalate concentration and temperature
This means that the better gas-sensing and thermal transfer properties can be achieved for coating formed under these conditions.

The nanoscale grain size coating increased the surface area and enhanced the metal surface characteristics because of the increasing surface-to-volume ratio which increases the quantum effect. The nanocoating has the same effect because the fined surface increases the surface area of the substrate material. The smaller the grain size, the larger the ratio of surface area to volume. Therefore, the heat transfer can be improved by the nanocoating technique. Furthermore, the higher surface area for gas sensors means that the sensors have more exposure to the targeted gas and greater ability to detect gas presence at lower concentrations. Therefore, the nanocoating technique can contribute to develop a device for heat transfers and gas sensors by increasing its efficiency and reducing its size, which are considered as among the most important industrial challenges.

\section{Effects of Solution Speed on Coating Characteristics}

The characteristics of coatings prepared at the same operating condition with different solution speeds were compared to investigate the relation between solution speed and coating microstructure. The effects of coating solution speed on thickness, grain size, and porosity were evaluated to investigate its effect on the total surface area. The same set of coating experiments was carried out under three solution speeds of $0.00,0.18$, and $0.55 \mathrm{~m} / \mathrm{s}$. Figure 8 shows that the grain size and porosity of coating prepared in $0.3 \mathrm{M}$ concentration were decreased with increased solution speed and decreased temperature.

The results also show that the minimum grain size and porosity were obtained for the coating prepared in $0.1 \mathrm{M}$



Fig. 8 Grain size and porosity of coating as a function of temperature and solution speed 




Fig. 9 The grain size of the coating as a function of oxalate concentration and solution speed

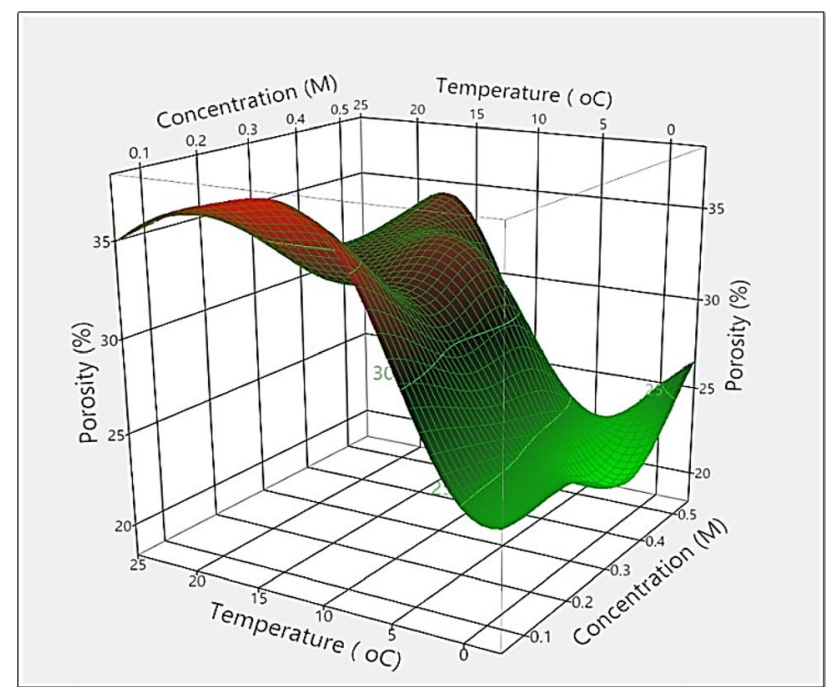

Fig. 10 Porosity of coating as a function of oxalate concentration and solution speed

oxalate concentration under the maximum solution speed of $0.55 \mathrm{~m} / \mathrm{s}$ as illustrated in Figs. 9 and 10 .

From the calculated total surface area of the nanocoated samples formed under various solution speed, the highest surface area was achieved for the sample prepared in the lowest oxalate concentration of $0.1 \mathrm{M}$ and lowest temperature as illustrated in Figs. 11 and 12.

Previous study found that the solution speed of the coating solution is an effective noise factor in the coating

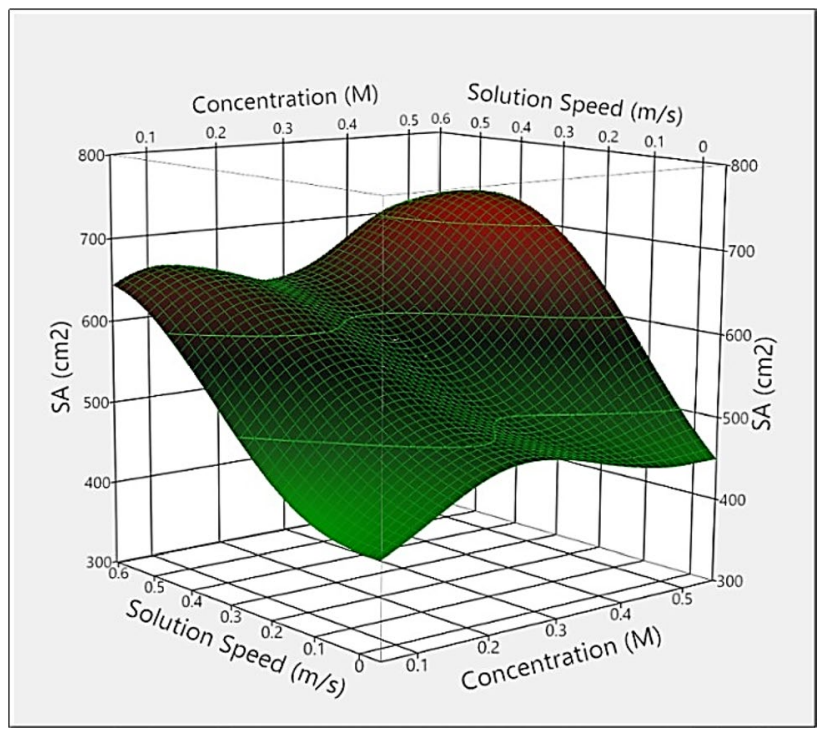

Fig. 11 The total surface area of coating as a function of oxalate concentration and solution speed

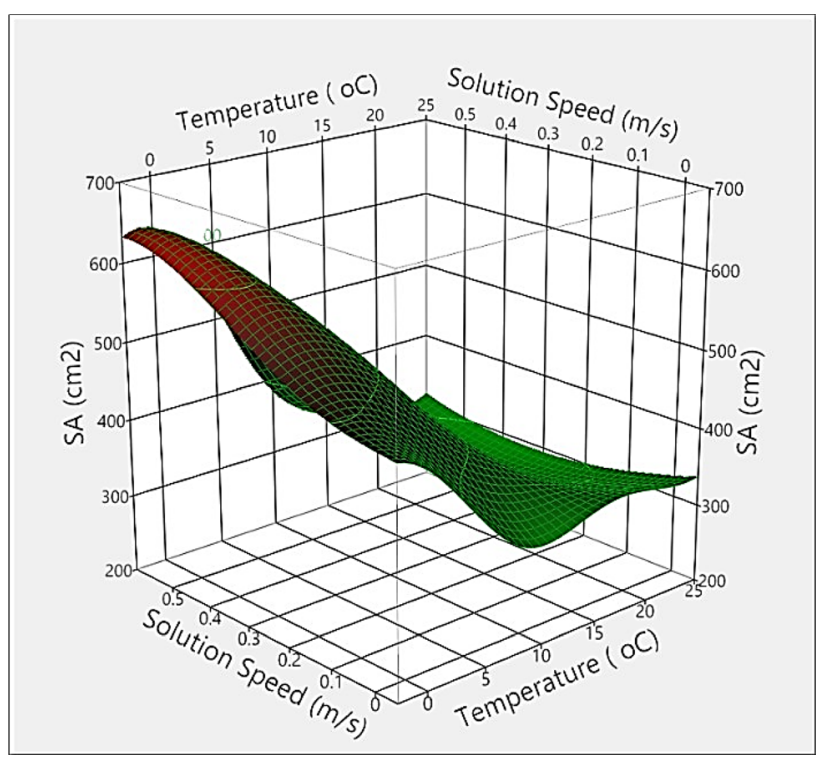

Fig. 12 The total surface area of coating as a function of temperature and solution speed

process which improves the ionic and charging transfer activity through the coating solution to form a nonporous coating with smaller grain size [23]. As a conclusion, based on the current investigation, it can be said that the better gas-sensing and thermal transfer properties are attainable from the nanocoating technique with effective parameters of the process, especially oxalate concentration, speed, and temperature of the coating solution. 




Fig. 13 The testing system for gas-sensing performance

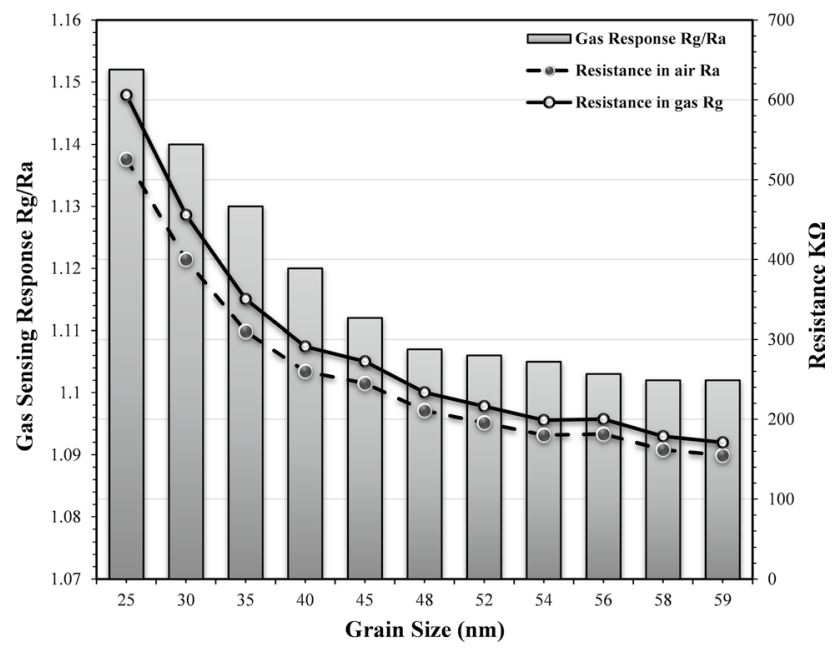

Fig. 14 Gas-sensing performance and resistance of coating as a function of grain size

\section{Gas-Sensing Performance}

The gas-sensing performance was tested using an experimental system consists of a test chamber with temperature controller, and voltmeter samples fixed on a heater tape plate over a ceramic holder. The inlet gas was controlled by a gas flow meter and passed through a block valve. Finally, vent gas was absorbed in methanol solution before releasing to atmosphere as illustrated in Fig. 13.

The sensing response of nano- $\mathrm{CuO}$ coated samples to $\mathrm{CO}$ gas was tested in a chamber. Then, the quantity of targeted CO gas (typically 200 ppm) was injected into the testing chamber. The resistance of sensor was recorded when it reached a constant value after $27 \mathrm{~min}$. Then, the testing chamber was vented. The inverse relation between the grain size and resistance was observed from the recorded resistance for various nanocoated samples. The results show that the resistance of coating surface (in air and gas) was increased with the decrease in grain size as shown in Fig. 14.

Figure 14 shows that the highest percentage of $\mathrm{CO}$ gas-sensing response of 1.15 was achieved for nano- $\mathrm{CuO}$ coating of the smallest grain size. The highest percentage of $\mathrm{CO}$ gas sensitivity for nano- $\mathrm{CuO}$ coating was increased by $50 \%$ from 10.2 to 15.2 with the decrease in coating grain size from 59 to $25 \mathrm{~nm}$ as illustrated in Fig. 14. The increase in resistance of coating with the decrease in grain size is due to the enhancement of the total surface area with the reduction of grain size, as previously discussed in Sect. 3.2.

From all the above, it can be concluded that the gas-sensing response of the coating was increased by improving the surface area through decreased oxalate concentration and temperature, in addition to increased speed of the coating solution to $0.55 \mathrm{~m} / \mathrm{s}$.

The present study provides more technical details about the effect of the surface grain size, porosity, and solution speed on the gas-sensing performance. It confirms the good sensitivity of the nano-CuO coating prepared by the electrochemical oxidation method in oxalic acid solution to $\mathrm{CO}$ gas. These results are compatible with the previous results of the nano- $\mathrm{CuO}$ coating prepared by the heating method at a temperature of $500{ }^{\circ} \mathrm{C}$ for $5 \mathrm{~h}$ [26]. The effect of coating grain size was significantly enhanced the response to $\mathrm{CO}$ gas reaching compatible sensitivity with other research studies for $\mathrm{CuO}$ nanowires prepared at $350{ }^{\circ} \mathrm{C}$ and decorated with $\mathrm{Pd}$ nanoparticles [27]. It confirmed the significant influence of these surface characteristics on the sensing performance. Furthermore, the thermal effects of nano-CuO coating on the heat transfer efficiency of copper were also investigated [28]. The results reveal that the efficiency of heat transfer was enhanced by $96.5 \%$. The enhancement was achieved by adjusting the effective parameters of the coating process, especially oxalate concentration, speed, and temperature of the coating solution, which increased the surface area about 350 times [28].

\section{Conclusions}

From the current study, the following notes can be concluded;

1. The thickness of coating increased with the increase in oxalate concentration at fixed coating temperature. The increase in coating thickness was due to the increase in electrical conductivity of the coating solution which led to increased coating rate.

2. The highest surface area was achieved for the coating prepared in the highest oxalate concentration and the lowest temperature.

3. The speed of the coating solution is an effective noise factor in the coating process. Increased solution speed has improved the ionic and charging transfer and formed a nonporous coating with smaller grain size. 
4. The $\mathrm{CO}$ gas sensitivity of nano- $\mathrm{CuO}$ coating was increased by $50 \%$ due to the improvement of the surface area with decreased oxalate concentration and temperature at fixed solution speed of $0.5 \mathrm{~m} / \mathrm{s}$.

5. The increase in surface area by the nano- $\mathrm{CuO}$ coating enhanced the efficiency of heat transfer by $96.5 \%$.

\begin{abstract}
Acknowledgements The authors would like to acknowledge the financial grant support given from sponsorship by Aljawda Enterprise, Warehouse 37 Tampines ST 92. Singapore. The authors also greatly acknowledge Research management Center of IIUM for giving this opportunity under PDRF scheme.
\end{abstract}

Open Access This article is licensed under a Creative Commons Attribution 4.0 International License, which permits use, sharing, adaptation, distribution and reproduction in any medium or format, as long as you give appropriate credit to the original author(s) and the source, provide a link to the Creative Commons licence, and indicate if changes were made. The images or other third party material in this article are included in the article's Creative Commons licence, unless indicated otherwise in a credit line to the material. If material is not included in the article's Creative Commons licence and your intended use is not permitted by statutory regulation or exceeds the permitted use, you will need to obtain permission directly from the copyright holder. To view a copy of this licence, visit http://creativecommons.org/licenses/by/4.0/.

\section{References}

1. Maki, S.A.; Mahmoud, O.A.: The thickness effect of $\mathrm{CuO}$ thin films on electrical and gas sensing properties. JMEST 4, 76527658 (2017)

2. Hojabri, A.; Hajakbari, F.; Soltanpoor, N.; Hedayati, M.S.: Annealing temperature effect on the properties of untreated and treated copper films with oxygen plasma. J. Theor. Appl. Phys. (2014). https://doi.org/10.1007/s40094-014-0132-x

3. Kimpa, M.I.; Yabagi, J.A.: Effect of oxidation temperature on the properties of copper oxide thin films prepared from thermally oxidised evaporated copper thin films. Artic. IOSR J. Appl. Phys. 3, 61-66 (2013)

4. Figueiredo, V.; Elangovan, E.; Gonçalves, G.; Barquinha, P.: Effect of post-annealing on the properties of copper oxide thin films obtained from the oxidation of evaporated metallic copper. Appl. Surf. Sci. 254, 3949-3954 (2008). https://doi.org/10.1016/j. apsusc.2007.12.019

5. Rydosz, A.: The use of copper oxide thin films in gas-sensing applications. Coatings (2018). https://doi.org/10.3390/coatings81 20425

6. Wang, C.: Metal oxide gas sensors: sensitivity and influencing factors. Sensors 10, 2088-2106 (2010). https://doi.org/10.3390/ s100302088

7. Khashan, K.S.; Sulaiman, G.M.: Synthesis and antibacterial activity of $\mathrm{CuO}$ nanoparticles suspension induced by laser ablation in liquid. Arab J Sci Eng 41, 301-310 (2016). https://doi. org/10.1007/s13369-015-1733-7

8. Sarica, N.; Alev, O.: Characterization and gas sensing performances of noble metals decorated $\mathrm{CuO}$ nanorods. Thin Solid Films 685, 321-328 (2019). https://doi.org/10.1016/j. tsf.2019.06.046

9. Ogwu, A.; Derma, T.H.; Bouquerel, E.: Electrical resistivity of copper oxide thin films prepared by reactive magnetron sputtering. Manuf. Eng. 24, 172-177 (2007)
10. Umar, A.; Alshahrani, A.A.; Algarni, H.: $\mathrm{CuO}$ nanosheets as potential scaffolds for gas sensing applications. Sensors Actuators B Chem. 250, 24-31 (2017). https://doi.org/10.1016/j. snb.2017.04.062

11. Manish, V.; Chowdhuri, A.; Sreenivas, K.: Comparison of $\mathrm{H}_{2} \mathrm{~S}$ sensing response of hetero-structure sensor $\left(\mathrm{CuO}-\mathrm{SnO}_{2}\right)$ prepared by rf sputtering and pulsed laser deposition. Thin Solid Films 518, e181-e182 (2010). https://doi.org/10.1016/j.tsf.2010.03.162

12. Lin, T.; Lv, X.; Hu, Z.; Xu, A.; Feng, C.: Semiconductor metal oxides as chemoresistive sensors for detecting volatile organic compounds. Sensors 19, 233 (2019). https://doi.org/10.3390/ s19020233

13. Wan, X.; Wang, J.; Zhu, L.; Tang, J.: Gas sensing properties of $\mathrm{Cu}_{2} \mathrm{O}$ and its particle size and morphology-dependent gas-detection sensitivity. J. Mater. Chem. A 2, 13641-13647 (2014). https ://doi.org/10.1039/c4ta02659d

14. Zhang, J.; Qin, Z.; Zeng, D.; Xie, C.: Metal-oxide-semiconductor based gas sensors: screening, preparation, and integration. Phys. Chem. Chem. Phys. 19, 6313-6329 (2017). https://doi. org/10.1039/c6cp07799d

15. Wetchakun, T.; Samerjai, N.; Tamaekong, C.; Liewhiran, C.; Siriwong, V.; Kruefu, A.; Wisitsoraat, A.; Tuantranont, S.: Phanichphant, Semiconducting metal oxides as sensors for environmentally hazardous gases. Sensors Actuators B Chem. 160, 580-591 (2011). https://doi.org/10.1016/j.snb.2011.08.032

16. ASTM International: Standard Practice for Preparation of Copper and Copper-Base Alloys for Electroplating and Conversion Coatings. ASTM B281-88 (2019).https://www.astm.org/Standards/ B281.htm, https://doi.org/10.1520/B0281-88R19E01.

17. Mahmood, M.; Suryanto, H.: Study the influence of the anodizing process parameters on the anodized copper hardness. MATEC Web Conf. 130, 08003 (2017). https://doi.org/10.1051/matec conf/201713008003

18. De Los Santos Valladares, L.: Crystallization and electrical resistivity of $\mathrm{Cu}_{2} \mathrm{O}$ and $\mathrm{CuO}$ obtained by thermal oxidation of $\mathrm{Cu}$ thin films on $\mathrm{SiO}_{2} / \mathrm{Si}$ substrates. Thin Solid Films 520, 6368-6374 (2012). https://doi.org/10.1016/j.tsf.2012.06.043

19. Adkar, D.: Synthesis and characterization of nanoscale metals metal sulphides and metal oxides by novel polymer inorganic solid state reaction, Savitribai Phule Pune University, Chap 3, p 59 (2013). http://shodhganga.inflibnet.ac.in:8080/jspui/bitst ream/10603/90129/9/09_chapter3.pdf

20. Aguilar, M.S.; Esparza, R.; Rosas, G.: Time-dependent facile synthesis of $\mathrm{CuO}$ hedgehog-like nanostructures and their catalytic activity. J. Solid State Chem. 277, 46-53 (2019). https://doi. org/10.1016/j.jssc.2019.05.034

21. W. Conshohocken: ASTM International, E112, Standard Test Methods for Determining Average Grain Size, West Conshocken, vol. 96, pp. 1-26 (1996). https://doi.org/10.1520/E0112-10.Copyr ight

22. ASTM International, Standard Test Methods for Determining Area Percentage Porosity in Thermal Sprayed Coatings. ASTM E2109-01 (2014). https://www.techstreet.com/standards/astme2109-01-2014?product_id=1883904

23. Mahmood, M.H.: Development of Anodized Copper Coating in Oxalate Containing Solution and Its Characteristics. Universiti Islam Antarabangsa Malaysia, (2019)

24. ASTM International: Standard Test Method for Measurement of Metal and Oxide Coating Thickness by Microscopical Examination of Cross Section, Standard. ASTM B487 - 8502.05 (2013). https://doi.org/10.1520/B0487-85R13

25. Zerbino, J.: Effect of oxalate on the growth of cuprous oxide layers on copper electrodes. Ellipsometric and isoelectric point study. Acta Chim. Slov. 56, 124-130 (2009) 
26. Dhanasekaran, V.; Mahalingam, T.: Electrochemical deposition and characterization of cupric oxide thin films. Thin Solid Films 520, 6608-6613 (2012). https://doi.org/10.1016/j.tsf.2012.07.021

27. Steinhauer, S.; Singh, V.; Cassidy, C.: Single $\mathrm{CuO}$ nanowires decorated with size-selected Pd nanoparticles for $\mathrm{CO}$ sensing in humid atmosphere. Nanotechnology 26, 1-6 (2015). https://doi. org/10.1088/0957-4484/26/17/175502

28. Mahmood, M.; Maleque, M.A.: Anodized nano-coating of copper material for thermal efficiency enhancement. The Mattingley Publishing Co., Inc. Test Eng. Manag. 83, 1430-1437 (2020) 